\title{
BLOOD AND LYMPH CIRCULATION UNDER NORMAL CONDITIONS AND IN CIRCULATORY HYPOXIA
}

\section{Vadim Astashov ${ }^{1 *}$, Valentin Kozlov ${ }^{1}$, Tatiana Tsekhmistrenko' ${ }^{1}$, Viktor Sidorov², Olga Gurova', Yulia Antsyreva ${ }^{7}$}

\author{
1 Peoples Friendship University of Russia (RUDN University), Moscow, \\ Russia; \\ ${ }^{2}$ LLCNPP «Lazma», Moscow, Russia
}

*Corresponding Author: vastashov3@gmail.com
Article history:

Submitted 4 April 2019

Accepted 20 May 2019

\begin{abstract}
The aim of the study was to assess the indices of blood and lymph microcirculation in the skin in healthy men under normal condition and in circulatory hypoxia. Thirty healthy men, aged 19 to 27 , were examined. Evaluation of blood and lymph circulation was carried out by laser Doppler flowmetry (LDF) of the skin - the palmar surface of the base of thumb. The results showed that in occlusal period an increase in the lymph flow and decrease in blood flow were revealed, compared to normal conditions. In post-occlusal period a rapid recovery of blood circulation and slight decrease in lymph circulation were observed. Conclusion. Indices of blood and lymph circulation differ in normal conditions, in occlusal test and in post-occlusal period. Different reactivity of blood and lymph microvessels is observed in circulation recovery. The data obtained can be used for the diagnosis of blood and lymph flow disorders and assessment of local toxicosis severity under various pathological conditions.
\end{abstract}

KEYW ORDS - blood microcirculation, lymph microcirculation, laser Doppler flowmetry, palm skin.

\section{| NTRODUCTION}

The issues of prevention and treatment of various circulatory disorders constitute an urgent problem of modern medical practice [3, 4]. Microcirculatory - tissue system is a structural-functional complex consisting of parenchymal elements, cellular and non-cellular component of connective tissue, blood and lymph microvessels, nerve fibers, combined into a whole system by regulatory mechanisms [12]. The lymphatic system is closely connected with the venous part of bloodstream, providing additional to veins drainage of organs. In the middle of $20^{\text {th }}$ century it was proved that every part of human body has a regional lymphatic apparatus, consisting of prelymphatic pathways, lymph vessels and lymph nodes and providing local detoxification and the maintenance of water and immune homeostasis [10]. Malfunction of the regional lymphatic apparatus causes accumulation of metabolic products and xenobiotics in intercellular space with the development of local endotoxicosis and exacerbation of chronic and acute pathologic conditions. In this regard, examination of the local blood and lymph flow in normal and pathological processes is important for development of diagnostic criteria for local and general endotoxicosis and severity of drainage-detoxification malfunction.

Laser Doppler flowmetry (LDF) is a modern non-invasive method for evaluating microcirculation. Registered Doppler frequency shift of the reflected signal is proportional to the speed of movement of the microvasculatory particles $[3,6,11,14]$.

Functional tests in LDF allow identifying the adaptive reserves of microcirculation, as well as regulatory mechanisms and functional condition of microvascular bed. One of the most used in the clinical practice is the occlusal test [9]. Since in clinical pathology ischemia is the dominant mechanism underlying general pathological processes, assessment of its tolerance allows, on the one hand, identifying the individual reactivity of vascular bed, and on the other hand, assessing the contribution of local and systemic mechanisms to its regulation [7].

The aim of the study was to examine the indices of blood and lymph microcirculation in the skin in healthy men under normal conditions and in circulatory hypoxia.

\section{MATERIALS AND METHODS}

Thirty healthy men aged from 19 to 27 years, were examined. Registration of changes in blood and lymph circulation in the microvasculature was carried out.

Examination of blood and lymph circulation in the skin was performed using LDF - standard probe holder put on the palmar surface of the base of thumb (tenar) in sitting position.

The study was performed using laser analyzer "LAZMA MC-1" (LLC NPP "LAZMA", Moscow, Russia; registration certificate of Roszdravnadzor № RZN 2015/3142 dated 10.28.2015), intended for evaluation of tissue blood and lymph circulation. The index of tissue blood circulation, determined by LDF method, is proportional to the product of the erythro- 
cytes number and the average speed of their movement (range $0.5-5 \mathrm{~mm} / \mathrm{s}$ ). The index of lymph circulation is proportional to the product of the number of diffusers in the lymph flow and the average speed of their movement $(10-40 \mu \mathrm{m} / \mathrm{s})[3,4,6]$.

The design of the study was as follows: we recorded the initial level of tissue blood and lymph circulation for 60 seconds (normal conditions), and then the recording was stopped. In the pressure cuff, put on the middle third of the shoulder, air was pumped up to $250 \mathrm{mmHg}$, and then the recording was continued. After $1 \mathrm{~min}$, with release of the pressure, reaction of microcirculation was recorded during restoration of blood flow over the next minute. The total time of the test was 3 minutes. LDF registration and occlusive test were performed by the same person (physician) with the same instrument (LAZMA MC-1 analyzer; manometer).

The perfusion indices were calculated using the software attached to LAZMA MC-1 analyzer. The dynamics of average microcirculation index in perfusion units (PU), its standard deviation (or flux level $-\sigma$ ), and the variation coefficient were determined. The microvascular reactivity index, characterizing post-occlusal hyperemia, was calculated in $\%$ in postocclusal period; indices in occlusal period were taken as $100 \%$. Blood (B) and lymph (L) circulation indices were processed using methods of variation statistics, statistical significance was determined using Student's criterion. Threshold for statistical significance was determined as $0.05[8]$.

\section{RESULTS}

Characteristic quantitative changes of blood (B) and lymph $(\mathrm{L})$ circulation indices were revealed. The indices are shown in the Table 1. hyperemia in the skin blood microvessels was $228 \%$, and the lymph index dropped by $27 \%$, compared to the occlusion level. The indices of blood and lymph circulation in occlusal test were statistically significant.

Thus, the data obtained indicate different dynamics of blood and lymph circulation in occlusal test and post-occlusal period.

\section{DISCUSSION}

In occlusal test not only the brachial artery is involved in the compression area but also the deep and superficial veins of the shoulder. This allows us to suggest transient hypoxia in the distal parts of the upper limb.

Earlier studies by other authors have not shown the extensive changes in the lymph flow on the first day of arterial ischemia. There are numerous data on the compensatory-adaptive activation of the lymph flow in the development of local venous hypertension [1]. According to Starling, the increasing lymph flow in venous stasis is caused by the following factors: high blood pressure in the veins increases capillary pressure; increased hydrostatic pressure in the blood capillaries leads to ultrafiltration in the interstitium, and resorption in the venous part of capillary becomes difficult. Excess fluid is absorbed from the interstitium into the lymph capillaries increasing the lymph flow $[1,4]$.

Thus, some increase in lymph production and lymph flow in our study seems to be a mechanism of compensation for the venous insufficiency in occlusal period. Based on the literature data and our results, it can be concluded that the functional test revealed the fact of lymph filing in the tissues in local venous hypertension.

In the post-occlusal period we found a rapid recovery of blood circulation with index exceeding the

Table 1. Indices of blood and lymph circulation in the tenar skin in normal conditions and in circulatory hypoxia $(M+m)$

\begin{tabular}{|l|l|l|l|l|l|l|l|l|}
\hline \multirow{2}{*}{ Area of examination } & \multicolumn{2}{|l|}{ Normal conditions (PU) } & \multicolumn{2}{l|}{ Occlusal test (PU) } & \multicolumn{2}{l|}{ Post-occlusal period (PU) } & \multicolumn{2}{l}{ Reactivity of microvessels \% } \\
\cline { 2 - 9 } & B & L & B & L & B & L & B & L \\
\hline Skin in the tenar area & $11,82+1,70$ & $0,29+0,06$ & $3,17+0,56^{*}$ & $0,46+0,05^{*}$ & $12,33+1,56$ & $0,38+0,05$ & +288 & -27 \\
\hline
\end{tabular}

* the differences are statistically significant if $P<0.05$.

In occlusal period the index of blood circulation decreased by $73 \%$ compared to normal conditions, and the index of lymph circulation, on the contrary, increased by $58 \%$. In the re-perfusion period, the index of blood circulation increased, compared to normal, by $4 \%$, while the lymph circulation index decreased by $31 \%$. The index characterizing reactive post-occlusal initial level by $4 \%$, while the lymph circulation index decreased by $31 \%$.

In this connection, it can be assumed that even partial occlusion of the upper limb leads to vein hypertension and hypoxia that contribute to increase in lymph production, lymph tissue filling and increase in interstitial pressure. This seems to cause a slower re- 
covery of microcirculation indices in the post-occlusal period.

Our data are supported by a number of studies showing that tissue fluid balance depends on many factors, including angioarchitecture, intensity of tissue blood flow and rheology of blood, but the key role is played by directed transport of protein molecules from the bloodstream to the lymph flow $[3,13]$.

\section{CONCLUSION}

The results of our study - blood and lymph circulation assessment using the LDF method - enable us to conclude that indices of blood and lymph circulation differ in normal conditions, in occlusal test and in post-occlusal period. Different reactivity of blood and lymph microvessels is observed in circulation recovery. The data obtained can be used both to diagnose disorders of the blood-lymph flow and to assess the severity of local toxicosis in tissue microdistricts under various pathological conditions.

This publication was prepared with the support of the "Program of the University of People's Friendship University of 5-100" in the framework of the initiative threads № 030210-0 -000

\section{REFERENCES}

1. Borodin YU.I., Grigoryev V.N. Lymph node in circulatory disturbances. /Novosibirsk: Nauka. Siberian Branch. 1986. - 266 p.

2. ZhDANOv D.A. Anatomy and physiology of lymphatic system. /Leningrad. Medgiz.1952. - 333 p.

3. Kozlov V.I., Duvansky V.A., Azizov G.A., Gurova O.A., Sidorov V.V. Laser Doppler flowmetry (LDF) and optic tissue oximetry in assessment of condition and disturbances of blood microcirculation. Methodological recommendations FMBA Russia. M. 2014. - 59 p.

4. Kozlov V.I. Capillaroscopy in clinical practice. M: Practical medicine.2015. - 231 p.

5. KONENKOV V.I., BORODIN Y.I., LUBARSKY M.S. Lymphology. Novosibirsk: Manuscript. 2012. $1104 \mathrm{p}$.

6. Krupatkin A.I., Sidorov V.V. Functional diagnostics of condition of microcirculatory and tissue systems. Fluctuations, information, nonlinearity. // Guide for doctors. M. 2013. - 496 p.

7. Kulikov V.Y., Polkovnikova O.V., Efremov I.A. Use of laser Doppler flowmetry in assessment of individual variants of vascular bed reactivity in local hypoxia. //Medicine and education in Siberia. 2015. Vol. 4. - http://ngmu.ru/cozo/mos/article/text_full. php?id=1845.

8. Lapach S.N., Chubenko L.V., Babich P.N. Statistical methods in biomedical research using Excel. K.: Morion. 2001. - 408 p.
9. Prokofyeva T.V., Polunina O.S., Yatsenko M.K., Maklakova N.V. Occlusal test in patients with stable angina pectoris class III I the course of inpatient treatment with LDF testing. //Uspechi sovremennogo estestvoznaniya. 2007. Vol. 12-1. Pp 129-131.

10. Rusnyak I., Feldi M., Sabo D. Physiology and pathology of lymph circulation. Budapest. 1957. - 856 p.

11. Khalepo O.V., Molotkov O.V., Zinchik V.V., DUVANSKY V.A. ET AL. Microcirculation and endothelium function: theoretical foundations, diagnostic principles, clinical practice. Scientific and methodological manual. Smolensk: OOO Duet-Print. 2015. - 112 p.

12. Chernukh A.M., Aleksandrov P.N., Alekseev O.V. / Microcirculation. M: Medicine. 1975. - 456 p.

13. Casley-Smith J.R. Lymph and Lymphatics in Microcirculation. /Eds.: G.Kaley, B.M. Altura. Univ. Park Press. 1977. T. 31. P. 421-502.

14. Ticcinelli V., Stankovski T., Iatsenko D, Bernjak A, Bradbury A. E., Gallagher A. R., Clarkson P. B. M., McClintock P. V. E. AND Stefanovska A. Coherence and Coupling Functions Reveal Microvascular Impairment in Treated Hypertension / Frontiers in Physiology, 13 October 2017. https://doi.org/10.3389/fphys.2017.00749 